\title{
LONGITUDINAL PHOTOGRAPHIC OBSERVATION OF THE OCCURRENCE OF BUBBLES IN PIT AND FISSURE SEALANTS
}

\author{
OBSERVAÇÃO FOTOGRÁFICA DA OCORRÊNCIA DE BOLHAS EM SELANTES DE \\ FÓSSULAS E FISSURAS
}

Renato Herman SUNDFELD ${ }^{1}$, Theodore P. CROLL ${ }^{2}$, Silvio José MAURO ${ }^{3}$, André Luiz Fraga BRISO ${ }^{3}$, Rodrigo Sversut de ALEXANDRE ${ }^{4}$, Maria Lúcia Marçal Mazza SUNDEFELD ${ }^{5}$

\author{
1- DDS, MSc, PhD - Associate Professor - Department of Restorative Dentistry of Araçatuba Dental School - São Paulo State University - \\ UNESP - Araçatuba - Brazil. \\ 2- Private practice, Pediatric Dentistry, Doylestown, Pennsylvania, USA; Associate Clinical Professor, Department of Pediatric Dentistry, \\ University of Texas Health Science Center at San Antonio (Dental School); Affiliate Faculty, Department of Pediatric Dentistry, University of \\ Washington School of Dentistry. \\ 3- DDS, MSc, PhD - Assistant Professor - Department of Restorative Dentistry of Araçatuba Dental School - São Paulo State University - \\ UNESP - Araçatuba - Brazil. \\ 4- Graduate Student, Department of Restorative Dentistry, Piracicaba School of Dentistry - Unicamp, Piracicaba, Brazil \\ 5- DDS, MSc, PhD - Assistant Professor - Department of Social Dentistry of Araçatuba Dental School - São Paulo State University - UNESP \\ - Araçatuba - Brazil.
}

Corresponding address: Renato Herman Sundfeld, Discipline of Restorative Dentistry - Araçatuba Dental School - UNESP. Rua José Bonifácio 1193, São Paulo, Brazil. Cep.: 16015-050. e-mail: sundfeld@terra.com.br Telefax: 551836363332.

Received: April 8, 2005 - Modification: July 1, 2005 - Accepted: September 6, 2005

\begin{abstract}
$T_{\text {he }}$ fissure sealants Concise and Prisma Shield, at 7 days, 18 months, 36 months and 11 years after accomplishment of treatment. Methods: A hematoxylin-based staining solution was applied to the occlusal surface at the study periods, which allowed assessment of the sealing material on the surface. All occlusal surfaces were photographed and the photographs corresponding to each period were subjected to photographic evaluation. Results: There was statistically significant difference only at 18 months, with a significantly higher number of specimens with bubbles for the Prisma Shield sealant compared to the Concise, whereas the groups were similar at all other study periods. On the other hand, separate analysis of subsequent periods of the sealants did not reveal any significant difference. Conclusions: According to the results of the present longitudinal investigation, it may be concluded that the sealing materials showed that bubbles came into and went out with time. However, this fact did not interfere with its clinical purpose, provided the remaining material covers the expected region of pits and fissures.

Uniterms: Pit and fissure sealants; Photographic study; Longitudinal study; Bubbles.
\end{abstract}

\section{RESUMO}

A

avaliação fotográfica para observar a presença ou a ausência de bolhas nos selantes de fóssula e fissuras Concise e Prisma Shield aos 7 dias, 18 meses, 36 meses e 11 anos, após a realização dos selamentos. Metodologia: Foi aplicado na superfície oclusal, em todos os períodos de análise, uma solução corante a base de hematoxilina, que possibilitou a verificação e a avaliação dos materiais seladores presentes nesta superfície. Todas as superfícies oclusais foram fotografadas e as fotografias, correspondentes a cada período em análise, foram submetidas à avaliação fotográfica. Resultados: Verificou-se diferença estatisticamente significativa somente aos 18 meses de análise, com o selante Prisma Shield apresentando um número significativamente maior de bolhas superficiais, que o selante Concise; enquanto que os demais grupos apresentaramse estatisticamente semelhantes entre si, em todos os outros períodos de análise. Por outro lado, quando os selantes foram analisados isoladamente, nos períodos subseqüentes, não foi observada a presença de diferença estatisticamente significativa.Conclusão: De acordo com os resultados observados, pudemos verificar que os materiais seladores apresentaram o aparecimento e o desaparecimento de bolhas, fato que não interferiu na finalidade clínica do selamento realizado. Unitermos: Selantes de fóssulas e fissuras; Avaliação fotográfica; Estudo longitudinal; Bolhas. 


\section{INTRODUCTION}

The complex anatomical design of pits and fissures allows considerable retention of food debris and microorganisms, a situation which is worsened by the difficult self-cleaning and improper toothbrushing at this area. Considering these factors, the carious lesions may be initiated in the pits and fissures soon after eruption ${ }^{1}$, leading to tooth loss if not prevented or treated. However, the utilization of pit and fissure sealants to obliterate these enamel defects hinders their initiation and consequently their development. The literature shows that the rationale of obliteration of pits and fissures was initiated with Gore ${ }^{2}$ in 1939, who investigated the utilization of cellulose nitrate in organic solvent.

Similarly, after the first case report of pit and fissure sealants by Cueto and Buonocore ${ }^{3}$ (1967), many studies have documented their real effectiveness for caries prevention ${ }^{4-11}$, further demonstrating that several occlusal surfaces receiving application of sealants remain sealed for several years after application ${ }^{8-12}$. In fact, these reports were corroborated by Simonsen ${ }^{8}$ in 1991 and Sundfeld, et al. ${ }^{12}$ in 2004, who reported that occlusal sealants analyzed 15 and 11 years after application, respectively, exhibited excellent retention rates of the material and also prevented carious lesions in pits and fissures. For this the application technique is fundamental for longevity of the material on the tooth surface $^{8,12}$.

It should be considered that, besides the marginal alterations that may be detected on time ${ }^{8-12}$, an accurate overall clinical analysis of the surface of sealants may demonstrate the came into and go out of bubbles. These demonstrate that sealing materials undergo surface wear ${ }^{12-}$ ${ }^{14}$ as teeth are positioned in the dental arch, as a consequence of the movement of eruption and joint adaptation, and also due to attrition with the food bolus. So, the present photographic evaluation was conducted to observe the came into and go out bubbles at 7 days, 18 months, 36 months and 11 years after sealing.

\section{MATERIALS AND METHODS}

The patients selected were subjected to a detailed clinical examination of the occlusal surface under artificial light and radiographic assessment by bitewing radiographs. The teeth selected presented clinically and radiographically intact proximal surfaces. For to reduce the experimental error the examiner was oriented about the operative steps, and also calibrated concerning the evaluation of the oral status of the patients, initial instructions especially as to oral hygiene, by adequacy of toothbrushing and routine flossing. The study protocol was approved by the Human Subject Review Committee (Araçatuba - UNESP).

\section{Experimental Design}

Forty-two premolars of 10 patients aged from 12 to 14 years were sealed. In 21 specimens, the light-cured Concise sealant $^{\mathrm{a}}$ (3M) (S1) was used, while the others were sealed with light-cured Prisma Shield sealant ${ }^{\mathrm{b}}$ (Caulk \& Dentsply) (S2). Occlusal sealing of pits considered sound, which corresponded to 36 specimens, was initiated by dental prophylaxis with pumice and water, followed by isolation with rubber dam, acid etching of the entire occlusal surface with $37 \%$ phosphoric solution acid for two minutes and washing and drying ${ }^{9}$. The chemically cured sealant Concise sealant $^{\text {a }}$ (S1) was applied to the occlusal pits and fissures with a bristle brush, and the light-cured Prisma Shield sealant $^{\mathrm{b}}$ (S2) was applied with a brush and immediately cured with a halogen light source (Fibralux Dabi Atlante) for 40 seconds.

Meanwhile, 6 specimens that had pits or fissures with minor located chromatic alterations, suggestive or not of the presence of an incipient caries lesion, were prepared with a smooth carbide $1 / 4$ round drill (K.G. Sorensen), to remove only the areas of chromatic alteration, keeping light pits and fissures intact. Then, after dental prophylaxis, isolation with rubber dam, acid etching of dental enamel on the entire occlusal surface, including the conservative cavities, and careful washing and drying of the occlusal surface, the conservative cavities received a thin layer of adhesive material (Prisma Bond ${ }^{\mathrm{c}}$ - Caulk/Dentsply), which was light-cured for 20 seconds.

A single layer of composite resin (Full Fill ${ }^{\mathrm{d}}$ - Caulk/ Dentsply) was then immediately placed only inside the conservative cavity, with no overlap on the borders ${ }^{15}$. Light curing of the composite resin was carried out for 40 seconds. Thereafter, all pits and fissures of the occlusal surface and the composite resin surface were brushed with either Concise $^{\mathrm{a}}$ (3M) (S1) or Prisma Shield ${ }^{\mathrm{b}}$ (Caulk \& Dentsply) (S2) light-cured sealants, as performed on the teeth without chromatic alterations.

On the $7^{\text {th }}$ day after sealant application, as well as after 18 months, 36 months and 11 years, a staining solution, as proposed by Ohkubo, et al. ${ }^{7}$ in 1982, was applied to all occlusal surfaces for 2-3 minutes. This solution is characterized by the capacity of staining the enamel surface highlighting the contour of the sealant margins, thereby allowing identification of its limits and also of the presence or absence of bubbles on the sealant surface. At these periods, all occlusal surfaces of all specimens were frontally photographed, so that the edge, the body and the sealant surface could be clearly seen. A Nikon camera equipped with a 2x magnification Medical lens was used. After the photo shooting session, the bluish coloring caused by the hematoxylin in the solution was immediately removed by application of $1 \%$ sodium hypochlorite. The photographs of each specimen taken at the aforementioned study periods were analyzed and compared to one another for analysis of the presence or absence of bubbles on the sealant surface over time. The comparative photographic analyses carried out at 7 days, 18 months, 36 months and 11 years after sealing were performed by only one experienced examiner. The number of surfaces analyzed for both sealants was greater than the number of teeth used in the study because some teeth presented, since the onset, 2 distinct sealed 
surfaces in the same occlusal surface (Figure 1).

The results were then analyzed for comparison of the performance of the two sealing materials at the aforementioned periods and subjected to statistical analysis for separated comparison of the sealants at each study period, by the chi-square test or Fisher's exact test, at a significance level of 5\%. Similarly, the non-parametric Cochran's Q test was used for comparison of each sealant in the sequence of the 4 study periods, since these were related data.

\section{RESULTS}

Initially, this study comprised 10 patients, adding up to 42 occlusal sealings on 42 premolars; however, 11 years later, only 8 patients participated in the photographic analysis of the sealants. Two patients could not attend the 11-year evaluation, being one with 8 sealed teeth and the other with 2 sealed teeth.

Thus, the occlusal sealings of 32 premolars were assessed as to the presence of bubbles, considering only the patients attending all evaluations, excluding the specimens not assessed in the 11-year evaluation from the assessments at the initial period (7 days) (T0), 18 months (T1) and 36 months (T2).

The 32 occlusal surfaces received application of Concise (S1) or Prisma Shield (S2) sealant in a similar manner, and allowed photographic evaluation (Graphic 1) of 38 surfaces, being 20 for the Concise sealant (S1) and 18 for the Prisma Shield sealant (S2), at all study periods.

Observation of the photographs of each specimen in all study periods revealed that, for both sealant materials, bubbles came into and went out. The Fisher exact test has shown a significant difference between the two sealants only at 18 months ( $\mathrm{p}=0.0311$ ) with Prisma-Shield presenting a greater number of specimens with bubbles than Concise (Table 1). On the other evaluation periods the comparisons have shown similar results between Concise and PrismaShield: at T0 the Chi square test with $\mathrm{p}=0.1395$; at T2 and T3 the Fisher exact test with respectively $\mathrm{p}=0.3836$ and $\mathrm{p}=0.1814$. The separate analysis of subsequent periods for the two sealants using the Cochran Q test was also non significant (Table 2) (Figures 2 and 3).

\section{DISCUSSION}

The introduction of acid etching by Buonocore ${ }^{16}$ in 1955 has made the sealing of occlusal surfaces effective. In fact, the findings of Buonocore were very important to guide future investigations, as the literature available reveals that this author nearly "established" the basic guidelines required for achievement of mechanical bonding of a resin material to the dental enamel, which was not known then. Without his studies, there would probably be no consistent and considerably successful scientific works. This is based on results achieved by the present authors ${ }^{9-12,17}$ in the last years, which reveal that no sealant applied was completely lost. However, these years of investigations on pit and fissure sealants also reveal that the professional should really be aware of the need of correct application of this material; these factors undoubtedly act in combination for prevention of occlusal dental caries.

Specimens presenting color alterations of their occlusal fissures were restored with composite resin after removal of the alterations, followed by application of the pit and fissure sealant; in no case the resin material was exposed, since it
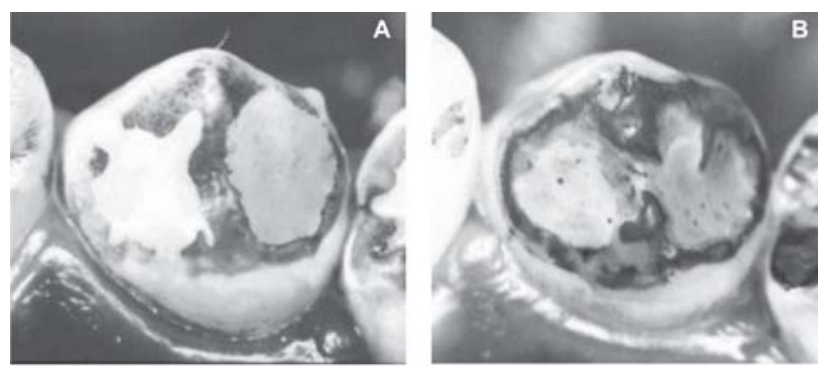

FIGURE 1- Photographs of specimens E26 and E27, left mandibular first premolar, presenting occlusal sealing at two distinct areas with the Prisma Shield sealant (S2), at the initial period (7 days) (T0) (A) and 11 years (T3) (B) after occlusal sealing

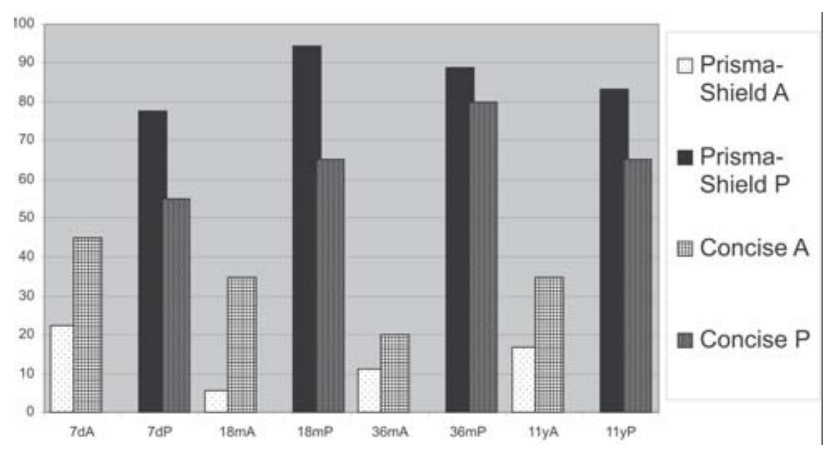

GRAPHIC 1- Absence (A) and Presence (P) of bubbles observed on the two sealing materials at the evaluation periods

TABLE 1- Concise (S1) and Prisma-Shield (S2) sealants, according to the presence or absence of bubbles after the occlusal sealing periods

\begin{tabular}{lllll}
\hline $\begin{array}{l}\text { Evaluation } \\
\text { Period }\end{array}$ & Prisma- Shield & \multicolumn{2}{l}{ Concise } \\
\hline & $\mathrm{A}$ & $\mathrm{P}$ & $\mathrm{A}$ & $\mathrm{P}$ \\
$7 \mathrm{~d}$ & 4 & 14 & 9 & 11 \\
$18 \mathrm{~m}$ & 1 & 17 & 7 & 13 \\
$36 \mathrm{~m}$ & 2 & 16 & 4 & 16 \\
$11 \mathrm{y}$ & 3 & 15 & 7 & 13 \\
\hline
\end{tabular}

$\mathrm{P}=$ Presence of bubbles.

$A=$ Absence of bubbles. 
was placed only inside the cavity without excess material. Similarly, Conry, et al. ${ }^{18}$, in 1992 conducted measurement of preventive restorations with composite resins and pit and fissure sealants by a profilometer computerized analysis, which revealed a largest thickness of sealing at the central area of the fissure or on the cavity restored with composite resin.

Thus, periodical analyses revealed, besides other alterations $^{15,17}$, an overall alteration of the surfaces of sealants, or even go out bubbles, which demonstrates that the sealing materials underwent wear as the teeth were positioned in the dental arch, as a consequence of eruption movements and joint adaptation, and also due to attrition between the food bolus and the sealant surface during chewing.

It should be highlighted that the natural wear of sealant occurring because of attrition during mastication and toothbrushing or due to occlusal contacts between teeth could be demonstrated by the came into and go out of bubbles in the sealants analyzed with time, with a clearer and more significant appearance in teeth receiving the filled sealant Prisma Shield (S2) at the 18-month analysis. This

TABLE 2- Results of Cochran Q test applied separately for each sealant

\begin{tabular}{lcccc} 
Sealant & $\mathbf{n}$ & $\begin{array}{c}\text { Degrees } \\
\text { of freedom }\end{array}$ & $\mathbf{Q}$ & $\mathbf{P}$ value \\
\hline Concise & 20 & 3 & 3.40 & 0.33 \\
Prisma Shield & 18 & 3 & 2,00 & 0.57 \\
\hline
\end{tabular}

No statistically significance difference between the four study periods.
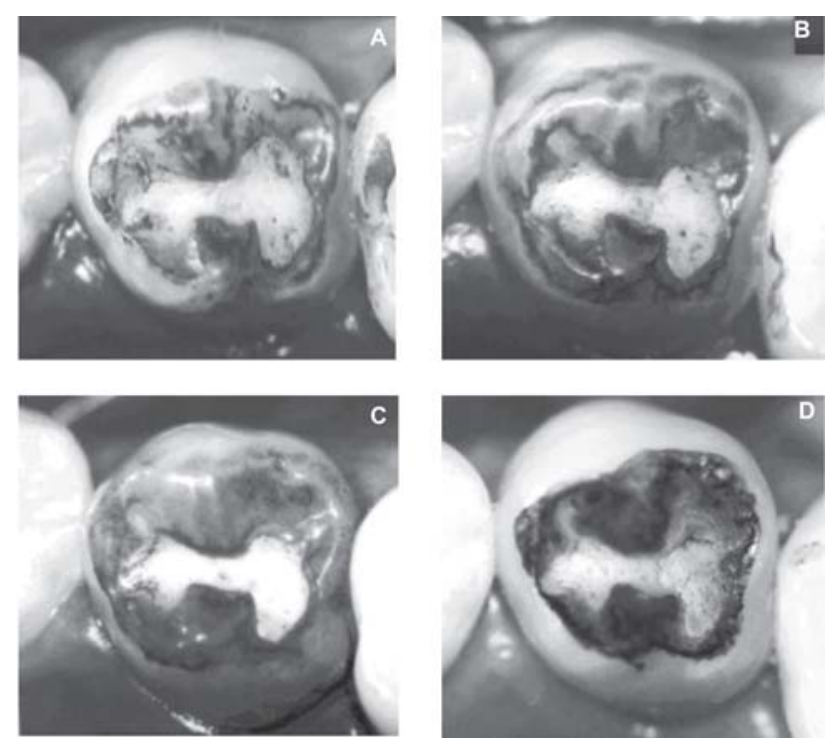

FIGURE 2- Photographs of specimen E08, left mandibular second premolar, presenting occlusal with the Concise sealant (S1), at the initial period (7 days) (T0) (A), 18 months (T1) (B), 36 months (T2) (C) and 11 years (T3) (D) after occlusal sealing fact might be related to the application method with a brush followed by immediate light-curing, which indeed could induce more incorporation of bubbles into the mass of the material.

Similarly, studies have reported that all sealings present a period of marginal loss ${ }^{7-12}$ and wear ${ }^{13,14,17}$, which expose areas previously covered by the sealing material, and that these areas with material loss are directly related to the anatomy and position of the tooth in the dental arch. After wear of the sealing material on the cuspal incline, the remaining sealing material was restricted to the pits and fissures and nearly out of occlusal contact, thereby presenting less material wear and after such accommodation. Then, the sealant is subjected to less wear, induced only by toothbrushing and by attrition with food during mastication. This may explain the similar performance of the Concise and Prisma Shield sealants when separately analyzed and between the study periods as to the came into and go out of bubbles with time.

According to the present results and to the findings of Tillis, et al. ${ }^{19}$, in 1992, within certain limits, the sealant should be susceptible to wear along time, since it is applied on the occlusal surface when teeth are still subject to accommodation and joint positioning in the dental arch. Thus, it might be inferred that the wear occurring with time will not interfere with its clinical purpose, provided the remaining sealant covers the desired area of pits and fissures, as also observed by Sundfeld, et al. ${ }^{12,17}$ (2003 and 2004).

Thus, this assumption might allow differentiation between the positive possibility of marginal and surface wear and the negative possibility of material loss because of improper application technique. Also, the presence of bubbles on the material bulk did not seem to interfere with its clinical purpose and should be a matter of concern only
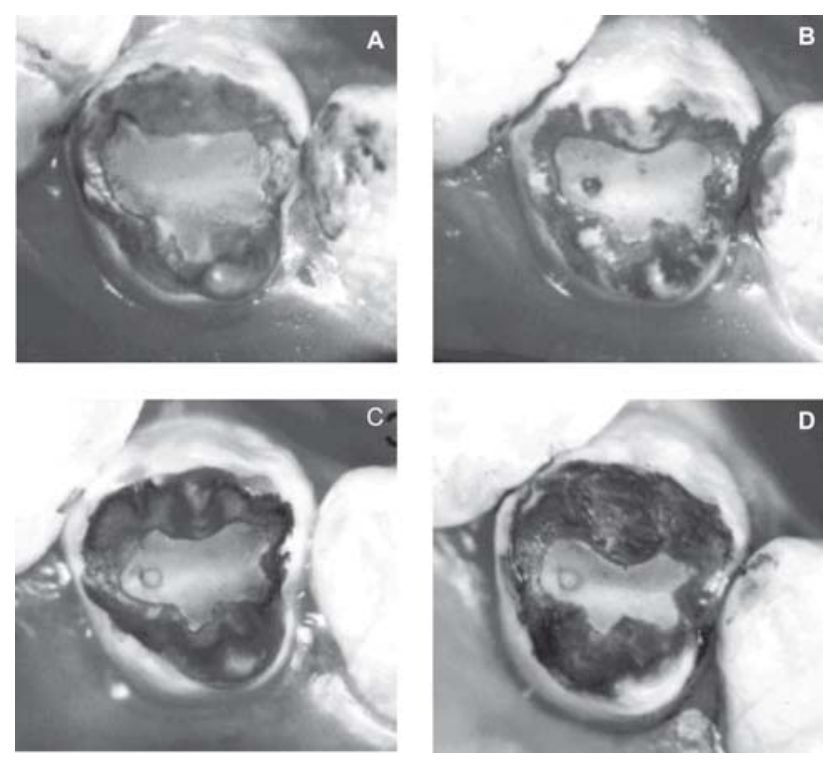

FIGURE 3- Photographs of specimen E38, left maxillary first premolar, presenting occlusal with the Prisma Shield sealant (S2), at the initial period (7 days) (TO) (A), 18 months (T1) (B), 36 months (T2) (C) and 11 years (T3) (D) after occlusal sealing 
when located at the sealant margin, i.e. at the interface between enamel and sealant, which might lead to initiation of carious lesions due to the possible accumulation of dental plaque and microorganisms at this interface. In an attempt to solve the possible formation of bubbles inside the sealant, Sundfeld, et al. ${ }^{11}$, in 1999, suggested application of lightcured filled sealants in occlusal pits and fissures under vibration, with aid of a dental probe, followed by light-curing only 10 second after application.

Moreover, factors as poor retention and material wear with time are also considered limiting factors for utilization of sealants by many professionals, which is not justified, since the present results and findings of previous studies of the same authors ${ }^{9-12,17}$ and other authors ${ }^{4-8}$ clearly confirm that correct application of every resin sealant provides an excellent retention rate of the material on the enamel surface.

Informatics currently allows considerable advances in all fields of science, as does in Dentistry. Pintado, et al. ${ }^{14}$, in 1988 suggested a method for quantitative and qualitative measurement of pit and fissure sealants applied on premolars “in vivo". This proposal included association of a sequential profilometer and an advanced computer software, which allowed recording of the presence of sealant, calculation of its volume and definition of its limit, indicating even the slightest alterations in occlusal contour, either quantitatively or visually, with aid of computer graphics. Similarly, Sundfeld, et al. ${ }^{17}$, in 2003, considering the increasing need to achieve more objective evaluating methods, used the clinical/ computerized evaluation, which allowed better definition of the sealed area, measurement and comparison between areas. This methodology provides numerical precision and favored a well-defined statistical analysis with objective outcomes. On the other hand, the clinical photographic evaluation presently employed may be considered a clinical evaluation able to detect the slightest alterations in sealing materials at the study periods investigated. This was possible because of the contrast provided by the dye on the sealant surface and between sealant and enamel, besides the possibility of comparison of photographs of a same tooth at distinct periods (Figures 1-3).

Thus, we believe that we are contributing for evolution of our profession, searching not only to treat the caries disease, but also and above all to prevent its appearance in pits and fissures, since no restorative material developed so far may fully replace the tooth structure.

\section{CONCLUSION}

Photographic evaluation of sealants applied on premolars indicated that, at 7 days, 18 months, 36 months and 11 years after sealing, bubbles came into and went out. This fact does not interfere with its clinical purpose, provided the remaining material covers the expected region of pits and fissures.

Batches and commercial brands of the resin materials employed.

a - Prisma Shield - Caulk \& Dentsply, Milford, DE, USA
- Batch - 7406

b - Concise - 3M, São Paulo Brasil - Batch - P 880105

c - Prisma Bond - Caulk \& Dentsply - Milford, DE, USA

- 6307/2

d -Full Fill - Caulk \& Dentsply- Milford, DE, USA - 7329

\section{ACKNOWLEDGEMENTS}

This research was supported by FAPESP grant n. 98/ 02814-3, São Paulo, Brazil.

\section{REFERENCES}

1- Reich E, Luss A, Newbrun E. Caries-risk assessment. Int Dent J. 1999;49:5-26.

2- Gore JT. Etiology of dental caries: enamel immunization experiments. J Am Dent Assoc. 1939;26:958-9.

3- Cueto EJ, Buonocore MG. Sealing of pits and fissures with an adhesive resin: its use in caries prevention. J Am Dent Assoc. 1967;75:121-8.

4- Croll T P. The quintessential sealant? Quintessence Int. 1996; 27:729-32.

5- Doyle WA, Brose JA A five year study of the longevity of fissure sealants. J Dent Child. 1978;45:127-9.

6- Mertz-Fairhurst EJ, Fairhurst CW, Williams JE, Della-Giustina VE, Brooks JD. A comparative clinical study of two pit and fissure sealants: seven-year results in augusta Ga. J Am Dent Assoc. 1984;109:252-5.

7- Ohkubo N, Iwata S, Chikada K, Kuriyama S, Narita M, Ishikawa T, Yoshida TA. Retention comparison of two sealants. Bullettin Tokyo Dent College. 1982;23:201-29.

8- Simonsen RJ. Retention and effectiveness of dental sealant after 15 years. J Am Dent Assoc. 1991;22:34-42.

9- Sundfeld] RH, Mauro SJ, Komatsu J, Mestrener SR. Retenção dos selantes: avaliação clínica fotográfica: 18 meses de análise. Rev Gaúcha Odontol. 1992;40:424-6.

10- Sundfeld RH, Komatsu J, Holland JR C, Hoeppner MG. Análise da retenção e da penetração de um selante com flúor (Fluroshield): estudo clínico e microscópico. Rev APCD. 1994;48:251-5.

11- Sundfeld RH, Mauro SJ, Holland JR C, Mestrener SR, Sundefeld MLMM, Briso A.L.F. Aplicação de selantes: confirmação de um recurso eficaz na prevenção das lesões de cárie de fóssulas e fissuras. Rev Bras Odontol. 1999;56:76-82.

12- Sundfeld RH, Mauro SJ, Briso ALF, Sundefeld MLMM Clinical/ photographic evaluation of a single application of two sealants after 11 years. Bull Tokyo Dent College. 2004;45:67-75.

13- Conry JP, Pintado M, Douglas WH Measurement of sealant surface area by computer. Quintessence Int. 1990;21:27-33.

14- Pintado, M, Conry, JP, Douglas, WH Measurement of sealant volume in vivo using image-processing technology. Quintessence Int. 1988;19:613-7. 
15- Simonsen RJ , Thompson V, Barrack G. Restaurações adesivas técnicas: clínica e laboratorial. São Paulo: Medicina Panamericana; 1985.

16- Buonocore MG. A simple method of increasing the adhesion of acrylic filling materials enamel surfaces. J Dent Res. 1955;34:84953.

17- Sundfeld RH, Mauro SJ, Dezan Jr E, Briso ALF, Sundefeld MLMM Measurement of sealant surface area by clinical/computerized analysis: 11-year evaluation. Quintessence Int. 2005 (in print).

18- Conry JP, Beyer JP, Pintado M.R., Douglas WH. Measurement of preventive resin restorations using computer profilometry J Dent Child. 1992;59:177-81.

19- Tilliss TS, Stach DJ, Hatch RA, Cross-Poline GN.Occlusal discrepancies after sealant therapy. J Prosthet Dent. 1992;68:223-8. 